\title{
The Proceedings
} of the Nutrition Society 


\title{
EDITED FOR THE NUTRITION SOCIETY
}

\author{
JOA N M. L. STEPHEN \\ Proceedings of the English Group \\ A. C. FIEL D \\ Proceedings of the Scottish Group \\ T. G. TA Y L O R \\ Chairman of the Editorial Board
}

The Nutrition Society has as its object the advancement of the scientific study of nutrition and its application to the maintenance of human and animal health.

Membership is open to any whose work has contributed to the scientific knowledge of nutrition, whether such work has been in the laboratory, the field or the clinic, and whether experimental, clinical, agricultural or statistical in nature.

Particulars of The Nutrition Society and application forms for membership may be had from the Honorary Secretary, Dr G. L. S. PAWAN, Metabolic Division, Department of Medicine, The Middlesex Hospital Medical School, London W1P 7PN.

The Proceedings of The Nutrition Society, published by the Cambridge University Press, in part, record meetings of the Symposium type, at which experts in a particular field are invited by Council to make contributions on specific parts thereof and at which general discussion follows these invited contributions. The contributions will be published in extenso; such summaries of the ensuing discussion as circumstances warrant may also be published. The Society also holds scientific meetings at which papers are communicated by members and others on original work carried out by them. It is proposed at present to publish summaries of the papers read at each meeting, each communication being recorded in the Society's Proceedings by means of an abstract not exceeding in length 400 words or the equivalent space in print. The Proceedings are published three times a year in May, September and December.

The British Journal of Nutrition is published by the Cambridge University Press for The Nutrition Society, which owns it and controls its publication. It is devoted to reports of original work in all branches of nutrition, the term 'original work' not implying that the papers must invariably be based on new facts. The British Journal of Nutrition does not print reviews of the literature or polemical articles, but the Editorial Board is willing to consider original articles critically re-examining published information and the conclusions drawn from it. A volume consists of three parts; two volumes are published each year.

Subscriptions to the Society's Publications. For non-members of The Nutrition Society the subscription to the Proceedings, including postage, is $£ 9.00$ per annum, payable in advance to the Cambridge University Press, Bentley House, 200 Euston Road, London NW1 2DB or to any bookseller. The subscription in U.S.A. is $\$ 27.50$, and inquiries should be addressed to the Cambridge University Press, American Branch, at 32 East 57th Street, New York, N.Y. 10022.

The annual subscription to the Journal is $£ 18.00$ net ( $\$ 55.00$ in the U.S.A.).

The price for single issues of the Journal is $£ 4.00$ (U.S.A. \$12.00). Single issues of the Proceedings are $£ 4.00$ net (U.S.A. \$12.00), postage extra.

A claim for the replacement of a publication lost in transmission will not be entertained if it is received more than 3 months after the date of posting. 